\title{
Nanotechnology in joint replacement
}

\author{
Ramón Torrecillas, r.torrecillas@cinn.es CINN-CSIC \\ José S Moya, jsmoya@icmm.csic.es ICMM-CSIC \\ Luis A Díaz, la.diaz@cinn.es CINN-CSIC \\ José F Bartolomé, jbartolo@icmm.csic.es ICMM-CSIC \\ Adolfo Fernández, a.fernandez@cinn.es CINN-CSIC \\ Sonia Lopez-Esteban, s.lopez@cinn.es CINN-CSIC
}

\begin{abstract}
KEYWORDS
Implantable materials, Joint replacement, Mechanical properties, Nanoparticles, Biomimetic materials
\end{abstract}

\begin{abstract}
This paper reviews the most relevant achievements and new developments in the field of nanomaterials and their possible impact on the fabrication of a new generation of reliable and longer lasting implants for joint replacement. Special emphasis is given to the role of nanocomposites with different microstructural designs: micro-nano composites, nano-nano composites, macro-micro-nano composites as well as bioinspired hierarchical composite materials. These nanostructured materials have opened up an exciting avenue in the design of non-metallic biocompatible, crack growth resistant, tough and mechanically resistant implants with a lifespan close to the life expectancy of the patients.
\end{abstract}

\section{INTRODUCTION}

Nowadays, the medical device market is immersed in ongoing continuous development, including approximately 5000 different types of products, and covering a broad range of technologies from Microelectronics to Microbiology. This growing market will always depend closely on the development of new concepts with regard to materials and technologies.

Firstly, as far as materials are concerned, much of this success has been traditionally achieved through the appropriate selection of existing materials, designed for different applications other than biomedical. For instance, many of the metal alloys typically used in prosthetic implants such as Ti-6Al-4V alloy were developed for the aircraft industry. However, at present, current research specifically on novel material concepts is already having an enormous impact on health care, and is widely used in prosthetic and drug delivery devices [1]. These novel material concepts are shaping the future direction of Biomaterials Science.

Nanotechnology is expected to become the transformational technology of this century, and therefore, along with other emerging technologies, it is also considered likely to enable the development of increasingly new concepts in medical device technology [2]. The possibilities for using engineered nanomaterials with diameters of $<100 \mathrm{~nm}$ in imaging and diagnoses, anticancer therapy, drug delivery, gene therapy and other areas have advanced rapidly. The potential for nanoparticles in these areas is infinite, with new applications constantly being explored. However, research into the possible toxic health effects of these nanoparticles associated with human exposure is still at a very early stage and needs to be pursued aggressively. Rigorous assessment is needed before some of the nanoparticles could be used with humans. [3-6]

Together with dentistry, orthopedics is one the medical fields to profit most from nanotechnologies, mainly in the field of implants for total joint replacement and resurfacing. Apart from mechanical stability, nanotechnology can provide some other necessary functionality to these devices (Figure 1). 


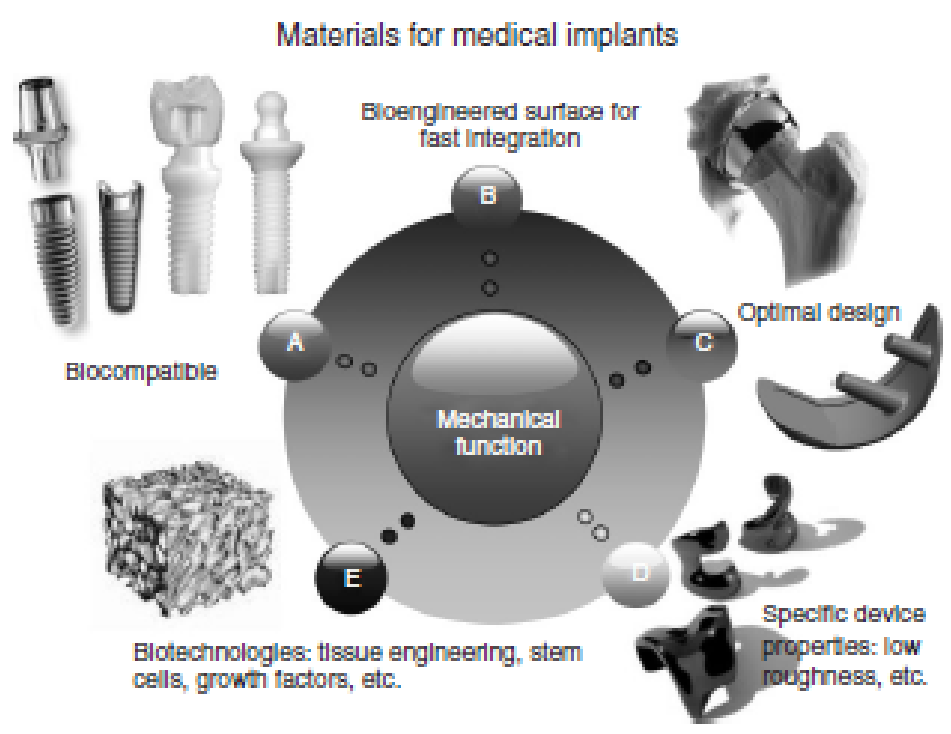

Figure 1 . Apart from mechanical stability, nanotechnology can provide other functionalities to medical implants.

These functionalities can consist of engineered surfaces for fast integration, high fatigue resistance enabling new, optimal designs, certain specific surface properties, such as low roughness (below $1 \mathrm{~nm}$ ), etc. This paper describes the most relevant developments achieved during the last ten years in the field of nanomaterials and which will certainly have a strong influence on the development of new, more reliable and long lasting joint replacement implants during the next ten years.

Nanocomposites promise an exciting future. New developments have shown the potential of ceramic nanocomposites, not only in orthopedics, but in the general field of implants. With only a reduction in size, an adequate microstructural design and no change in substance, nanocomposites can exhibit new properties, such as durability, wear resistance, greater strength, fatigue resistance, and greater reactivity characteristics that the very same substances do not exhibit in micro or macro scales.

This fact, coupled with the possibility to create bioinspired nano-architectures, opens the possibility to design new nanostructured bioinspired devices for total joint substitution with a lifetime higher that the life expectancy of the patient.

\section{JOINT REPLACEMENT BASICS}

Hip and knee joints are so-called cartilaginous joints. The joint surface is covered by a smooth articular surface that allows pain-free movement in the joint. The cartilage cushions the joint, and allows the bones to move smoothly. This surface can wear out for a number of reasons; often the real underlying cause is not known. When the articular cartilage wears out, the bone ends rub on one another and cause pain. Arthritis is the general term covering numerous conditions where the joint surface (cartilage) wears out [7].

Total Joint Replacement (TJR) procedure replaces all or part of the joint with an artificial device (prosthesis) to eliminate pain and restore joint movement. Today, orthopedic implants such as hip and knee prostheses have an average lifetime of about 10 to 15 years. However, considering an ageing population and the growing demand for orthopedic surgery from younger patients, implants should have a lifetime of more than 30 years.

Although over the past decade primary joint replacement has established a success rate of nearly 95 per cent, (i) the number of revision of total joint replacements (TJR) is increasing; (ii) the annual growth rate for revision implant products during the past several years has been estimated at nearly $12-15 \%$ - more than twice the growth for primary implants during the same period. 
Therefore in recent years, research has basically concentrated on three different issues: (i) the materials that can function safely and effectively as biomaterials in long-term implants; (ii) the right interface between the implant and the bone, termed fixation; and finally (iii) avoiding wear and debris of the bearing surface [8].

Regarding the interface between implant and bone, the focus of research in many laboratories around the world is the study of new methods to functionalize implant surfaces in order to improve their osseointegration. This property can be promoted by specific modification of material surface characteristics, thus improving beneficial interactions at the interface with the biological environment [9]. Many chemical and mechanical treatments are commonly applied to produce desirable features, even onto the surface of commercially available devices. Recent studies have shown that osteoblasts are sensitive to surface roughness, exhibiting decreased proliferation and a more differentiated phenotype on rougher surfaces. This can be considered as the "traditional approach" to design endosseous device surfaces. A new strategy to improve endosseous implant integration is based on preparing biomimetic surfaces able to present adhesive factors to cells. Osteoblast adhesion takes place by at least two different mechanisms: the most investigated one implies the interaction with RGD sequences via cell-membrane integrin receptors; a further mechanism concerns the interaction between cell-membrane heparan sulfate proteoglycans and heparin-binding sites of extra-cellular matrix proteins. The "biochemical approach" towards the design of endosseous devices opened the way for the search for biomolecules which are able to promote cell adhesion and adhesion strength onto the implant surface.

The implantation of synthetic materials into the body also elicits inflammatory host responses that limit medical device integration and biological performance. This inflammatory cascade involves foreign body reaction, fibrous encapsulation of the implant which eventually may become loose and leads to implant failure. This foreign body reaction might be controlled by the presence of protective coatings which provide long-term mechanical stability at the attenuate biofouling, leukocyte adhesion and activation interface, and adverse host responses to biomedical and biotechnological applications [10].

A forth issue related to non-invasive surgery has been addressed. Metal-on-metal total hip resurfacing has recently gained tremendous popularity as another hip replacement method. Metal-on-metal resurfacing in general involves a one-piece acetabular cup that is similar to that used in total hip replacement, and a femoral cap. The femoral resurfacing component is applied to the top of the femoral head with a minimal loss of bone. This technique is a bone-conserving alternative to conventional Total Hip Replacement (THR). Unlike Total Hip Prosthesis (THP), hip resurfacing does not involve the removal of the femoral head and neck or removal of bone from the femur. The head, neck and femur bone is rather preserved to facilitate future surgery, if necessary, and to enable the patient to take advantage of newer technology or future treatments. In the ' $70 \mathrm{~s}$ and early ' $80 \mathrm{~s}$ a metal-on-polyethylene design was used with poor results. Although recommended for the younger patient for whom future revision could be expected [11], rates of failure of up to $34 \%$ were reported at 30 months [12]. By the mid-1980s many articles describing the complications and failures of the procedure had been published [13-15]. Enthusiasm for resurfacing disappeared, although it was felt that the root of the problem may have been the materials used rather than the technique itself [16], and that new materials should be considered. Now, after around 20 years, a cumulative survival rate of $99.8 \%$ at four years for metal-on-metal hip resurfacing practice has been reported [17]

Nevertheless, the metal-on-metal surface of hip resurfacing leads to circulation of metal in the bloodstream. Cobalt and chromium ions can be detected throughout the body in patients who have had metal-on-metal hip replacements or hip resurfacing surgery and the possible negative effects are not yet completely known. Recent publications [18-19] express large concerns over hypersensitivity reactions and possible carcinogenic effects in the medium-short time.

Using ceramic surfaces could remove the problem of the metal ions. However, resurfacing techniques require more demanding design challenges, i.e. the thickness of the implant being too small for conventional ceramic materials.

Something similar happens in the case of knees. Not all patients need total knee replacements. Some patients with arthritis involving only part of the knee may benefit from unicondylar knee replacements. The 
advantages of using such replacements are the possibility of a shorter hospital stay, a smaller incision, and no replacement of the patella. Nonetheless, once again, the use of ceramics has been restricted for this application.

\section{MONOLITHIC MATERIALS AND COMPOSITES FOR HARD ON HARD JOINTS OBTAINED BY CONVENTIONAL ROUTES}

Hard on hard ceramic materials for Total Joint Arthroplasty have been produced for over 30 years, in an attempt to find an alternative to the CoCr-UHMWPE-bearing couple.

A great deal of research effort has been put into reducing debris generation and fracture risk. All these investigations were mainly devoted to two monolithic oxide ceramics, alumina and zirconia; consequently only those materials have been commercialized until now.

Recently, ceramic manufacturers have paid attention to ceramic composites [20], with alumina and zirconia as the main constituents of these materials. Since alumina and zirconia have demonstrated to be biocompatible ceramics, the main efforts have focused on the processing and reliability of such materials rather than a new microstructural design or the search for new materials and compositions.

In order to try to improve the characteristics of the monolithic ceramic materials, the focus shifted to the search for effects based on the reduction of the alumina and zirconia grain size. Currently, nanostructured raw materials with a crystal size of some nanometers are available; however if the nanostructure is to be maintained, serious problems exist during the conventional processing of these nanopowders into dense compacts.

Nevertheless, new sintering techniques for the reduction of the grain size are available [21]. For example, Figure 2 (position 2 of micro-micro composites) shows the microstructure on an alumina hip socket, obtained by near net shape spark plasma sintering, carried out in collaboration with M. Nygren at Stockholm University. Although the grain size is very small and the density is the theoretical value, the mechanical properties are not those deemed appropriate due to the fundamental fact that the strength (and toughness) of alumina depends very much on its grain size. Grain boundaries of sintered alumina contain tensile residual stress resulting from anisotropic thermal expansion, Young's modulus along the crystal axes, and show signs of crystallographic misorientation across grain boundaries. Therefore, in the case of sintered polycrystalline alumina, cracks can more easily propagate through grain boundaries than across the crystals. Consequently, when increasing the grain size of alumina, an increase in fracture toughness is observed, also due to the appearance of a reinforcement mechanism related to wake effects like bridging, crack deviation, etc. All these mechanisms disappear when reducing the grain size below a critical value. In this case grain boundaries are free of stresses, but contain numerous defects or dislocations, and the average fracture energy through grain boundaries can be higher than for the weakest alumina planes, normally the (0001) planes. Therefore this type of alumina with very small grain size presents a completely transgranular fracture surface, similar to glass. In this particular case, it thus makes no sense to fabricate nanostructured alumina compacts as structural monolithic material, unless other functionalities, such as high hardness (Hv about $23 \mathrm{GPa}$ ), translucency or transparency in the visible range are sought.

In the case of zirconia Y-TZP (Figure 2, position 3 of micro-micro composites), a very different analysis is required, although the final conclusion is the same. The mechanisms for operational reinforcement in the case of zirconia Y-TZP depend on the transformability of the zirconia grains, and therefore directly on the grain size if the quantity of the doping agent is not modified (for biomedical applications this is 3 mol \% of Yttria). Additionally, the ISO standard 13356 establishes the range of grain size of these materials for biomedical applications. An extra problem exists, as the same physical-chemical martensitic transformation process, which serves as a reinforcement mechanism, is responsible for the damage by the hydrothermal degradation or "ageing" of zirconia [22-23]. It was precisely this last mechanism which was responsible for the withdrawal from the market of one of the main producers for femoral heads worldwide. The addition of alumina to Y-TZP increases the mechanical performance of zirconia (Figure 2, position 4 of micro-micro composites), but does not resolve the ageing problem.

In summary, the reduction of the grain size in the nano range $(100 \mathrm{~nm})$ does not only result in a nonimprovement for the monolithic alumina and zirconia materials, but severely damages their behavior (Figure 2). 


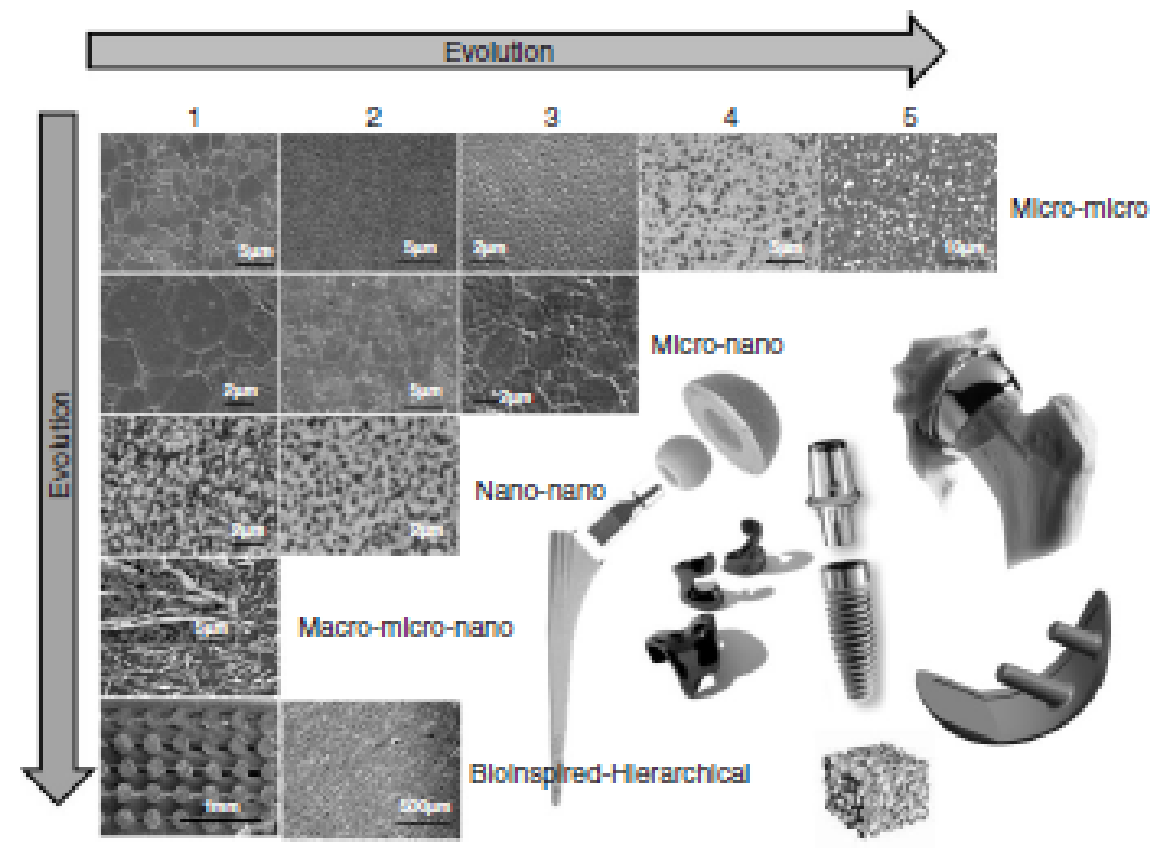

Figure 2 Vertical evolution from micro-nano to bioinspired hierarchical composites. Each horizontal line shows the evolution of each kind of composites as they try to ameliorate the mechanical performance of materials for medical devices.

Many attempts have been undertaken to increase the fracture toughness of alumina. Three decades ago, Garvie [24] published the first work on increasing the high fracture toughness of composites in the $\mathrm{Al}_{2} \mathrm{O}_{3}$ $\mathrm{ZrO}_{2}$ system by means of transformation toughening. Nowadays it is well known that this reinforcement mechanism depends on several factors, such as the zirconia content, the tetragonal-to-monoclinic zirconia ratio and other microstructural features. It has been shown that homogeneous microstructures with small zirconia particles and narrow particle size distribution of both alumina and zirconia particles [25] lead to important improvements in mechanical properties (see Figure 2, position 5 of micro-micro composites). On the other hand, the presence of agglomerates in the final compact decreases their mechanical performance drastically.

Conventional processing routes involve either dry milling [26] or wet milling [27] of a mixture of alumina and zirconia powders. By using these conventional processing techniques it is difficult to avoid the presence of some agglomerates and the microstructural homogeneity is limited, being detrimental to mechanical behaviour and the necessary reliability of the final components.

Nowadays, interest focuses on new powder processing techniques, like sol-gel, [28] where starting precursors are in a dissolved state, in order to obtain smaller particles with narrow particle size distributions and therefore better microstructures. However, low producing rates and other economical aspects make it unattractive from an industrial point of view.

In any event, by using powder mixture processing routes, alumina-zirconia composite materials have been studied [29] as an alternative to monolithic materials. However, it has been clearly demonstrated that when the amount of zirconia exceeds the percolation threshold estimated at 16 vol. \%, ageing phenomena reappear [30-32]. In a recent publication, Nakanishi et al [33], using commercial hip prosthesis with 13 vol. $\%$ zirconia content, have observed that no zirconia transformation took place. Conversely Pezzotti [34] et al. have shown transformation in commercial hip prosthesis with 18 vol. \% zirconia content. These results strongly confirm the prediction of the research by Pecharromán et al. [30].Therefore, the latest developments by Ceramtec with zirconia contents of about $17-25$ vol. \% should be carefully studied at long 
term [34]. However, alumina-non stabilized zirconia materials with zirconia contents below 12 vol. \% resulted in a considerable improvement in mechanical behavior, without the associated ageing problems [30-32]. Nevertheless, it has to be taken into account that the materials with reinforcement mechanisms based on zirconia transformation are thermodynamically unstable and as a consequence the lifetime will be always under suspicion when compared to other more stable materials.

\section{NANOCOMPOSITES FABRICATED FROM NANOSTRUCTURED POWDERS OBTAINED BY COLLOIDAL ROUTES}

\section{Micro-Nano Composites}

Micro-nano composites present mainly two phases: the matrix with a crystal size in the micron range of microns and a second phase constituted by nanometer sized nanoparticles located in intra- and intergranular positions. Nanocomposites yield dislocations around the particles and these dislocations release residual stress in the matrix. The dislocation field depends not only on the thermal expansion and elastic properties mismatch between the matrix and the nanoparticles, but also on the differences between surface energy and interface energy. In this way, alumina nanocomposites with $\mathrm{SiC}$ (lower thermal expansion coefficient (CTE), higher Young modulus (E)), YAG (similar CTE, similar E) and ZrO2 (higher CTE, lower E) have shown improved mechanical properties compared to monolithic alumina [35]. The important breakthrough of the nanomaterials and the effects associated to the nanostructure however, has been reached with alumina-zirconia nanocomposites.

A fundamental design parameter which is directly related to the lifetime or fatigue resistance, static or dynamic, of an implant is the threshold for the stress intensity factor $\mathrm{K}_{\mathrm{IO}}$, a security factor below which no subcritical propagation of defects or cracks occurs, and therefore an important parameter when designing a new ceramic material for structural applications, as in the case of hip or knee implants [36].

In order to obtain alumina-based nanocomposites, colloidal routes to obtain nanostructured multiphased powders have opened up a new avenue of research [37]. Starting from tailored alumina-nano zirconia powders following the aforementioned colloidal route (see Figure 3), researchers have developed a new class of dense nanocomposites with a microstructured alumina matrix and a second distribution of very small zirconia particles located at both grain boundaries and intragranular positions (Figure 2, positions 1 and 2 of micro-nano composites). It has been demonstrated that these nanocomposites present a unique property due to their nanostructure. It has in fact been discovered that they present a compressive residual stress field around zirconia nanoparticles embedded inside alumina crystals, retarding the crack front opening when applying an external stress, to stand in competition with the stress corrosion. It seems that the relative effect of the residual stress intensity factor is higher for lower applied stress intensity factors. Therefore, a higher slope in the nanocomposite $\mathrm{V}-\mathrm{K}_{\mathrm{I}} / \mathrm{K}_{\mathrm{IC}}$ curve is obtained, similar to the ones observed in covalent materials (Figure 3). The immediate implication of this increase of the $\mathrm{V}-\mathrm{K}_{\mathrm{I}} / \mathrm{K}_{\mathrm{IC}}$ curve slope on ceramic on ceramic implants is a lower sensitivity to delayed failure, as slow crack growth occurs for larger applied $\mathrm{K}_{\mathrm{I}} / \mathrm{K}_{\mathrm{IC}}$ values 


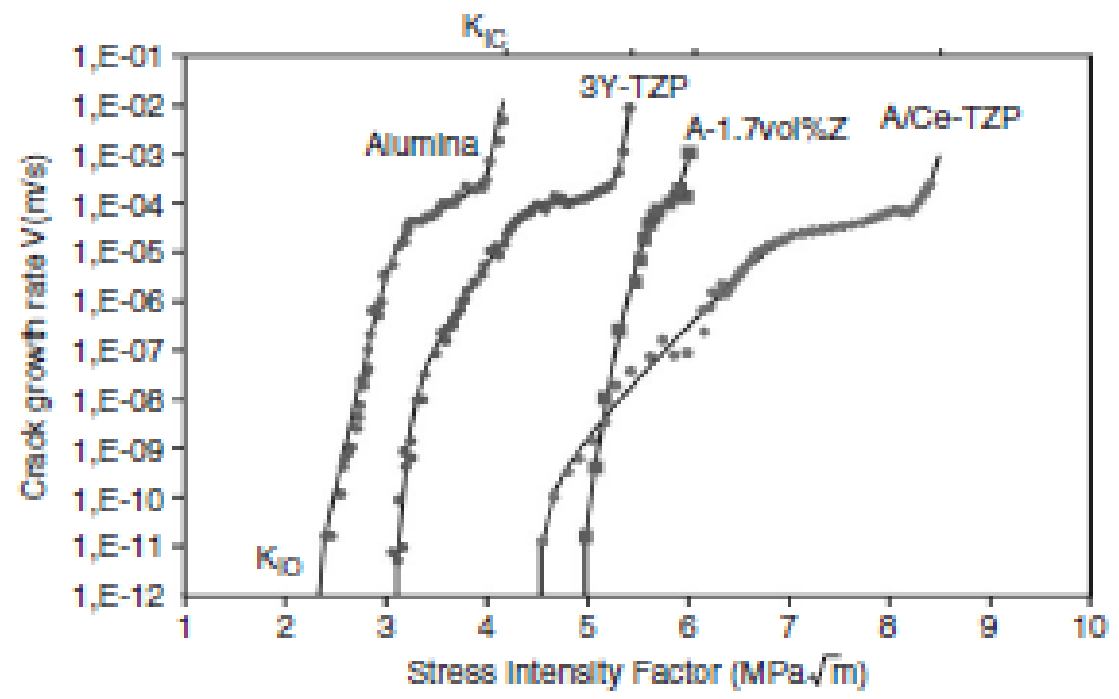

Figure 3 Slow crack growth curve showing lower sensitivity to delayed failure (slow crack growth occurs for larger applied $K_{\mathrm{I}} / \mathrm{K}_{\mathrm{IC}}$ values in the case of micro-nano composites Alumina-1.7 vol.\% Zirconia).

Near net shape acetabular components from nanostructured powders obtained by colloidal routes have been achieved by the authors of the present work in collaboration with M. Nygren at Stockholm University, by spark plasma technique. Figure 2, (position 3 of micro-nano composites) shows the obtained microstructure. The intricate microstructure with very small zirconia nanoparticles well distributed in the microstructure and originating a network of subgrains in the alumina matrix can be observed. This nanocomposite shows interesting mechanical properties and extremely high hardness ( $\mathrm{Hv}=24.3 \mathrm{GPa})$.

This result gives new insights for the development of biocompatible oxide ceramic-based nanostructured composites for implantology since they offer crack resistance similar to covalent materials without their major drawbacks associated with processing and machining [38-40].

\section{Nano-Nano Composites}

Nawa et al. [41] developed a Ce-TZP/Al2O3 nanocomposite (with both phases being on the 250-300 nm range) that exhibits an extremely high resistance to low-temperature degradation (ageing), a good biocompatibility and high wear resistance (Figure 2, position 1 of nano-nano composites) [42-44]. A recent work [45] has also shown that phase transformation is the main toughening mechanism operating in these nanocomposites and there is no need to highlight any 'nano' effect to account for the excellent crack resistance of the present nano-structured material. Nevertheless, these authors also pointed out that the $\mathrm{K}_{\mathrm{IC}} / \mathrm{K}_{\mathrm{IO}}$ ratio in the case of these nano-nano composites is higher than in the case of micro-nano composites mentioned above [39] where an important "nano" effect has been observed (Figure 4). This is clearly due to the fact that transformation toughening, and internal stresses produced when a nano phase is located inside another crystal, does not affect alike the $\mathrm{K}_{\mathrm{IC}}$ and $\mathrm{K}_{\mathrm{IO}}$ values. In the case of the nano-nano composite, although this microstructure has been described as an interpenetrated microstructure, the amount of nanoparticles found inside other crystals is quite low and as a consequence the $\mathrm{K}_{\mathrm{IO}}$ value is not affected by the effect associated with a network of dislocations in the sample. Additionally, as Ce-TZP presents a very important plasticity, which is at the same time the responsible for the observed important increase of toughness, stresses are relaxed during cooling after sintering. Then only the alumina grains containing isolated zirconia nanoparticles can contribute to the so called "nano effect". There is therefore a compromise between a transformation toughening effect, due to Ce-TZP, and the ability to induce internal stress capable of affecting the stress intensity factor threshold. 
Torrecillas et al. [46] have recently proposed a combined solution to obtain a nano-nano composite in this system, but using a colloidal route (Figure 2, position 2 of nano-nano composites). As a consequence, both Ce-TZP and alumina starting nanopowders ( 80 and $140 \mathrm{~nm}$ in size respectively) are coated with an alumina and zirconia precursor respectively. After processing, the obtained nanocomposites show a very fine nanostructure where the matrix is formed by Ce-TZP crystals showing a clear sub-grain structure constituted by the former crystals. Small alumina crystals $(<20 \mathrm{~nm})$ are retained inside Ce-TZP grains and other alumina grains $(200-300 \mathrm{~nm})$ are homogeneously distributed in the Ce-TZP matrix. These nano-nano composites obtained by conventional processing techniques using specially tailored nanocomposite powders, show flexural strength values in the range of 950-1000 MPa and fracture toughness around 12 $\mathrm{MPa} \sqrt{\mathrm{m}}$.
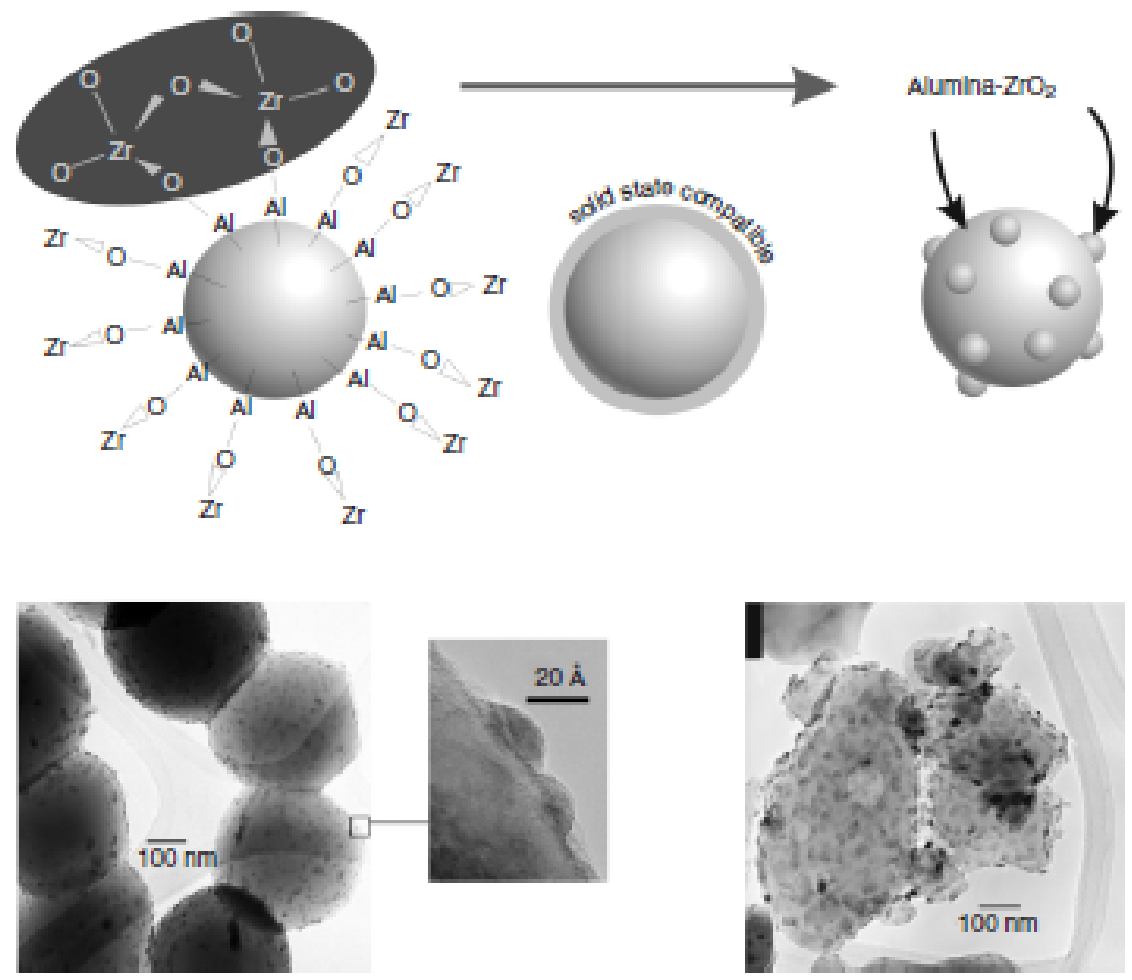

Figure 4 Alumina-1.7 vol.\% nanocomposite powders obtained by a colloidal processing route from two different starting powders [37].

\section{Macro-Micro-Nano Composites}

There is still a clear need for more crack-resistant or crack-tolerant designs in TJR ceramic devices. In these components, strength is determined by intrinsic flaws within the microstructure which may have been introduced into the material during processing $[47,48]$. Little attention has been paid to short crack growth resistance properties in terms of extrinsic flaw states. The same initially well-polished component may accumulate substantial damage during fabrication, machining or finishing [49,50], heat sterilization (ageing) [51], and even surgery (prosthesis handling and insertion procedures). Flaws can also be produced as a result of in vivo corrosion or degradation. Any imperfections will cause stress concentrations, and hence will cause one or more cracks to grow, causing fracture of the component [52]. Revision operations 
for fractured ceramic components are difficult, because the surgeon must carefully remove all fragments of the broken ceramic component. This is major surgery and the failure rate of these operations has been high, for instance up to $31 \%$ in Total Hip Arthroplasty revision [53]. We must take into account that for a structural life exceeding patient lifetimes, a minimum required detectable defect size is computed, which must be detected by quality-control procedures prior to the device entering service; this defect size is typically of the order of tens of microns for such ceramic implants, compared to sizes in the hundreds of microns for corresponding metal prostheses.

In designing damage-resistance bioceramic microstructures, it is important to distinguish between two philosophies: crack initiation and crack propagation. In this regard, it is often useful to partition the mechanisms of fracture into "intrinsic" and "extrinsic" processes [54]. Intrinsic mechanisms evolve ahead of the crack tip (independent of crack size) like the compressive residual stress in the case of aluminazirconia micro-nanocomposites described above. These micro-nanocomposites, with toughening mechanisms operating on a scale smaller than that of the matrix microstructure, can display a greater threshold for the stress intensity factor $\left(\mathrm{K}_{\mathrm{IO}}\right)$, under which crack propagation does not take place. But damage tolerance in these materials is low [55]. On the other hand, extrinsic mechanisms invariably evolve behind the crack tip. The aim of such latter mechanisms is to inhibit the propagation of existing cracks, either by enhancing crack bridging to increase alumina monolithic ceramics toughness, by transformation toughening mechanisms in zirconia ceramics or by both mechanisms in alumina-zirconia composite ceramics. One of the most effective methods to incorporate these mechanisms is by introducing a ductile metal secondary phase, such as particles, plates or fibres in ceramic matrix [56-59]. It is then possible to increase toughness with crack extension (R-curve) [60]. Such an increase in fracture resistance provides damage tolerance characteristics to composites and narrows their strength distributions [61]. However, these improvements are often achieved at the expense of strength for small flaws. Therefore, in terms of microstructural design, requirements for high strength are often different or even contradictory to those for high fracture toughness. As mentioned above, monolithic nanoceramic composites improve strength, but decrease toughness due to the lack of crack bridging. On the other hand, ceramic composites improve toughness and flaw tolerance, but give low strength. Some researchers have suggested that a compromise must be made between these requirements. Here the dilemma is whether to sacrifice strength to gain some flaw tolerance, or to improve strength at the expense of some flaw tolerance or toughness.

Recently a new macro-micro-nano composite has been manufactured [62], where toughening and strengthening are achieved through the incorporation to $\mathrm{Al}_{2} \mathrm{O}_{3}$ matrix of both $\mathrm{Nb}$ lamellar shape macroparticles and $\mathrm{ZrO}_{2}$ nanoparticles. Figure 2, position 1 of macro-micro-nano composites shows the microstructure of these composites. Niobium, being a refractory metal, was chosen because of its ductile constitutive behaviour and its biocompatibility. Niobium has been implanted in human tissue without causing inflammatory or allergic reactions. Along with its good radiopacity, niobium produces few magnetic resonance (MR) imaging artefacts [63]. It is important to point out that the paramagnetic nature of stainless steel and cobalt-chromium implants provokes an interaction with the magnetic fields present during MR imaging. This may result in device movement, device heating or development of an artefact on the collected image. This artefact problem is more critical on spinal implants.

The design of $\mathrm{Al}_{2} \mathrm{O}_{3}-\mathrm{ZrO}_{2} \mathrm{n}-\mathrm{Nb}$ macro-micro-nanocomposites opens the possibility to tailor new materials with toughening mechanisms operating at different scales, as in the case of natural bone, on a scale smaller than that of the matrix microstructure, that enhances the "intrinsic" fracture properties of the material. This intrinsic increase of resistance to crack initiation and propagation due to a structural synergism between the matrix and dispersoid phases, should lead to an increase in the catastrophic failure strength. On the other hand, extrinsic mechanisms, such as the bridging of ductile metallic elongated particles, can enhance crack growth resistance (R-curve) and flaw tolerance. In other words, in this case the increase in strength and toughness are compatible.

The knowledge of the respective influence of nano-, micro- and macro-scale mechanisms during crack initiation and propagation allows strategies to be defined for better crack growth resistance materials. These improvements in mechanical properties of macro-micro-nanocomposites turn them into promising candidates for new biomedical applications such as spine and knee components, as well as larger and thinner versions of existing components, such as ball heads and inserts. 


\section{BIOINSPIRED HIERARCHICAL MATERIALS}

The materials used in TJR are designed to enable the joint to move in the same way as the normal joint. Materials and surgical techniques are improving rapidly because of the efforts of orthopedists working with engineers and other scientists. Metals such as stainless steel, as well as cobalt, chrome, and titanium alloys have been successfully used for decades in fracture fixation, joint replacement, and dental applications [64]. Metallic orthopedic implants have serious shortcomings related to their osseointegration. Recent advances can be found in the literature regarding the fabrication of novel glass coatings to improve the bone/implant interface [65-70]. The glasses could be combined with other organic or inorganic materials to tune the coating resorption rates or to fabricate therapeutic coatings.

Despite this solution, current implants still have a fundamental flaw: The use of bioimplant materials with Young modulus higher than that of human bone produces negative effects of stress shielding and the corresponding bone loss. Flexible stems would be a possible solution, however they increase proximal interface stresses. Hence, the cure for bone resorption they represent may develop into increased loosening rates because of interface debonding and micromotion. The relationship between implant flexibility and the extent of bone resorption around hip stems does suggest that the changes in bone morphology are an effect of stress shielding and a subsequent adaptive remodeling process. This is a problem that still needs to be addressed [71]. Therefore, it is necessary to develop new materials specifically designed for orthopedic applications: bone-like biomaterials that will be treated by the host as normal tissue matrices, and induce cell penetration and proliferation after implantation, while their properties match those of the tissue to be repaired. This challenge could be met by novel hybrid organic/inorganic composites with an architecture controlled from the nano to the mesolevel. Tomsia et al have reviewed some of the recent efforts in the development of metallic and ceramic implants, and the most recent research in the field of organicinorganic hybrid composites for bone replacement [64].

It is worthwhile mentioning that, simultaneously, more research is devoted to a deeper knowledge of the natural material bone, as Ritchie et al show in a recent work [72]. Bone is a complex hierarchical composite of collagen and hydroxyapatite imbued with mechanisms to resist fracture at different size scales [73]. These size scales relate to the characteristic structural dimensions in bone, which vary from the nanoscale (twisted peptide chains) to the several hundred micrometers (the lamellar structure of collagen fibers). It is the simultaneous operation of toughening mechanisms at these various length scales that provides bone with its enduring strength and toughness. Taking into consideration this structure, the ideal bone substitute is a material that will form a secure bond with the tissues by allowing, and even encouraging, new cells to grow and penetrate. In this sense, nowadays there is ongoing research into several technologies seeking to obtain bioinspired hierarchical materials for implants. With the development of Tissue Engineering, the concept is changing from replacement to regeneration: it is necessary to fabricate bioresorbable threedimensional (3D) scaffolds (Figure 2, position 1 of bio-inspired-hierarchical composites). Two considerations must be taken into account to address the problem, which are, firstly, the material used and, secondly, the technique to obtain the structure as discussed in the following paragraphs.

First, regarding the material, it must be osteophilic and porous, so that new tissue, and ultimately new bone, can be induced to grow into the pores and help to prevent loosening and movement of the implant. E. Saiz et al [74] have recently pointed out the great effort which has been made in the development of porous scaffolds for bone replacement and tissue engineering [75-76]. Synthetic hydroxyapatite (HA) has been one of the materials of choice for the fabrication of inorganic scaffolds due to its close relationship with the mineral component of the bone and its excellent osteophilic properties [77].

Secondly, regarding current techniques, there is ongoing research into several technologies working towards obtaining bioinspired hierarchical implant materials. Direct ink writing (DIW) techniques offer a powerful route for producing complex $3 \mathrm{D}$ structures, including space-filling solids and structures with high-aspect ratio walls or spanning (unsupported) elements. The term "direct-write assembly" [78] broadly describes fabrication methods that use a computer-controlled translation stage, which moves a patterngenerating device, e.g., an ink deposition nozzle or laser writing optics, to create materials with controlled architecture and composition. Several direct ink writing techniques have been introduced that are capable of patterning materials in 3D, including 3D-printing, direct ink-jet printing, hot-melt printing, robocasting, fused deposition and micropen writing. In DIW, 3D structures are built layer-by-layer through the deposition of colloidal- or polymer-based inks. This approach allows ceramic materials in complex 3D 
shapes to be designed and rapidly manufactured without the need for expensive tooling, dies, or lithographic masks.

For instance, the use of computer-driven rapid prototyping techniques to produce porous ceramic with anisotropic microstructures is being investigated by several groups. Robocasting is a simple technique to produce porous ceramic parts with complex shapes. In robocasting, a ceramic ink is extruded through a thin nozzle to build a part layer-by-layer following a computer design. The ink must exhibit a controlled viscoelastic response. It should flow through the nozzle and subsequently settle very fast, bonding to the previous layer so that the part maintains its shape while printing (Figure 2, position 1 of bio-inspiredhierarchical composites).

The ideal fabrication technique should produce complex shaped scaffolds with controlled pore size, shape and orientation in a reliable and economical way [79]. However, all porous materials have a common limitation: the inherent lack of strength associated with porosity. Hence, their application tends to be limited to low-stress locations, such as broken jaws or fractured skulls. Therefore, the unresolved dilemma is how to design and create a scaffold that is both porous and strong.

Freeze casting [80] is a simple technique to produce porous complex-shaped ceramic or polymeric parts (Figure 2, position 2 of bio-inspired-hierarchical composites). In freeze casting, ceramic slurry is poured into a mold and then frozen. The frozen solvent acts temporarily as a binder to hold the part together for demoulding. Subsequently, the part is subject to freeze drying to sublimate the solvent under vacuum, avoiding the drying stresses and shrinkage that may lead to cracks and warping during normal drying. After drying, the compacts are sintered in order to fabricate a porous material with improved strength, stiffness and desired porosity. The result is a scaffold with a complex and often anisotropic porous microstructure produced during freezing. By controlling the growth direction of the ice crystals, it is possible to impose a preferential orientation for the porosity in the final material. Recently, Deville et al [38] have obtained porous hydroxyapatite scaffolds by freeze drying. The scaffolds have subsequently been infiltrated with a second organic phase with tailored biodegradability. Because the biodegradation rates of the scaffold and the infiltrated compound can be designed to be different, porosity can be created in situ to allow bone ingrowth. By using this approach, they have been able to fabricate HAP-based composites with stiffness $(10 \mathrm{GPa})$, strength $(150 \mathrm{MPa})$, and work of fracture $\left(220 \mathrm{~J} / \mathrm{m}^{2}\right)$ that match the one of compact bone for an equivalent mineral/organic content (around 60/40 vol. \%).

\section{FUTURE TRENDS}

Very recently, studies have pointed out that approximately $1 \%$ of patients with a metal-on-metal $(\mathrm{Co}-\mathrm{Cr}$ alloy) resurfacing will develop a pseudotumour within five years [18, 19]. These alarming results, together with reports of sensitization and/or elicitation of contact allergy to orthopedic metallic implants [81-83], are a clear indication that in the near future any toxic metal-containing implant has to be avoided. The trend is towards ceramics and ceramic/non-toxic biocompatible metal $(\mathrm{Nb}, \mathrm{Ta}, \mathrm{Ti}, \mathrm{Zr})$ composites. In this regard, nanotechnology offers a vast array of possibilities as we have indicated above. No simple solution exists. Hierarchical materials with complex microstructures like bone clearly emerged as the more appropriate approach. In Figure 5 we have selected two macro-micro-nanocomposites with high microstructural complexity obtained by two different methods (a) ice templated [80] and (b) powder processing with lamellar metal particulate [62]. In both cases the strength and toughness values have been drastically improved. Conversely to the monolithic, nano-nano and micro-nano composites, these complex materials offer high flaw tolerance behavior [59], similar to that of natural bone. On the other hand, these complex nanostructured materials are thermodynamically stable in vivo conditions. Then aging and slow crack growth problems can be drastically minimized. 

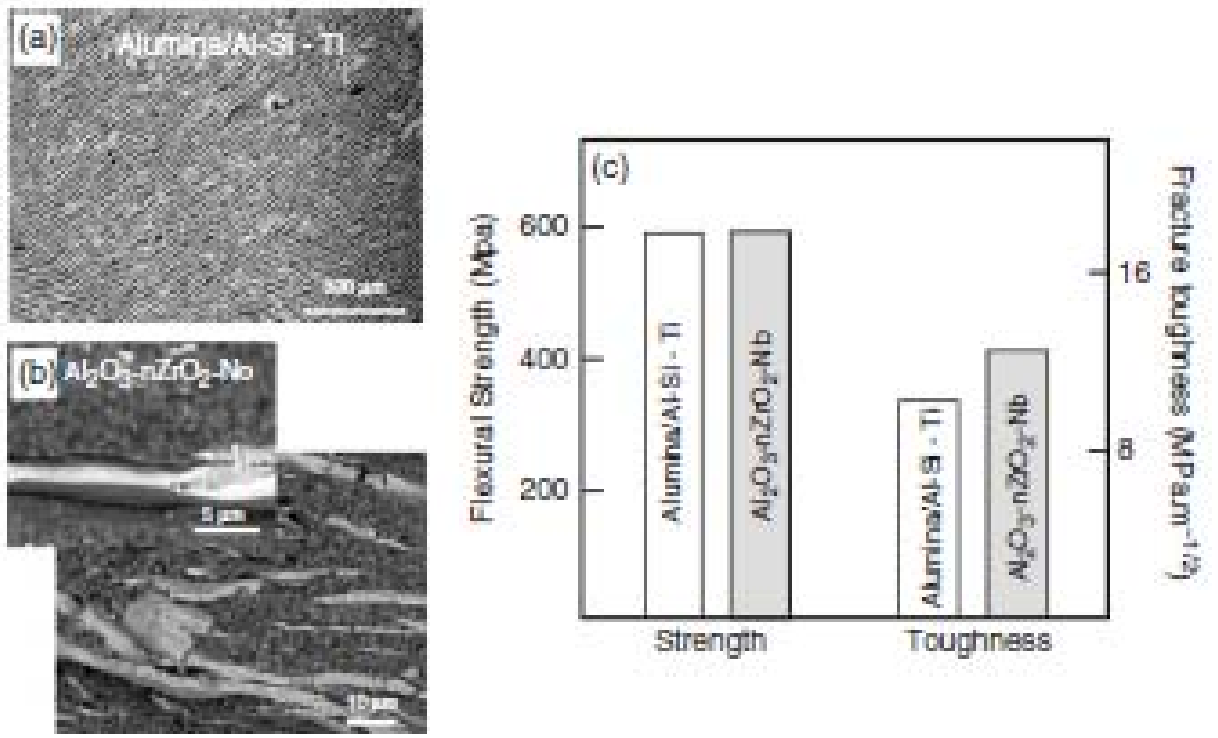

Figure 5 Macro-micro-nanocomposites with high microstructural complexity obtained by two different methods A) ice templated [80] and B) powder processing with lamellar metal particulate [62].

\section{CONCLUSION}

The future of joint replacement may see the implementation of a variety of materials specifically designed to fulfill the functionalities of the different natural materials constituting the natural joints.

The solutions which are currently used are not acceptable for many reasons: (a) some of them are made of non biocompatible metallic materials, produce debris due to wear and, as a consequence, have a short lifetime requiring several revisions (b) magnetic and non-magnetic metallic devices of certain geometries interact with the magnetic field when the patients are observed by MRI causing heating and even movement of the implant. Of secondary concern is the possibility of image artifacts that can compromise the procedure and image quality. Finally (c) there is an important mismatch between the elastic properties of currently-used materials and those corresponding to bone and cartilage. As a consequence there is not a good interface between implant and bone.

Taking into account the aforementioned reasons for a malfunctioning implant, a final solution based on a single material cannot be expected. While tissue engineering will not be able to give a final solution for artificial joints, different approaches start to achieve encouraging results: a) bioinspired hybrid organicinorganic hierarchical structures have shown to be serious candidates to replace Ti stems b) multi-scale modeling and design of composite multi-materials provide a combination of interesting functionalities. The control of the nanostructure can provide ceramic materials with better fatigue resistance in static and dynamic conditions. The control of the macrostructure can provide flow tolerant materials. The future combination of both materials and the customized search for adequate interfaces between dissimilar materials will crystallize in a new generation of longer-lasting implants for joint replacement, giving rise to aggressive geometries and designs that allow a less invasive surgery and a better quality of life for the patients.

\section{NOTES}

Authors would like to acknowledge the European Commission for its financial support under contract IP Nanoker, Contract number NMP3-CT-2005-515784. 


\section{REFERENCES}

[1] Langer, R, Tirrell, DA. Designing materials for biology and medicine. Nature 2004 428:487-492.

[2] Anderson, MK. Dreaming about Nanomedicine. Wired Magazine, November 2000.

[3] Gwinn, MR, Vallyathan, V. Nanoparticles: Health Effects-Pros and Cons. Environ Health Persp. 2006 114 (12):1818-1825.

[4] Linkov, I, Satterstrom, FK, Corey, LM. Nanotoxicology and nanomedicine: making hard decisions. Nanomedicine: NBM 2008 4(2):167-171.

[5] Jain, KK. Nanomedicine: Application of nanobiotechnology in medical practice. Med Prin Pract 2008 17(2):89-101.

[6] Cavalcanti A, Shirinzadeh B, Zhang MJ, Kretly LC. Nanorobot hardware architecture for medical defense. Sensors 2008 8(5):2932-2958.

[7] Hootman, JM, Helmick, CG. Projections of US prevalence of arthritis and associated activity limitations. Arthritis Rheum 2006; 54:226-229.

[8] Huo, MH, Parvizi, J, Gilbert, NF. What's New in Hip Arthroplasty. J Bone Joint Surg Am. 2006; 88:2100-2113.

[9] Bagno, A, Piovan, A, Dettin, M, Chiarion, A, Brun, P, Gambaretto, R, Fontana, G, Di Bello, C, Palù, G, Castagliuolo, I.Human osteoblast-like cell adhesion on titanium substrates covalently functionalized with synthetic peptides. Bone 2007 40:693-699.

[10] Bridges, AW, Singh, N, Burns, KL, Babensee, JE, Lyon, LA, Garcia, AJ. Reduced acute inflammatory responses to microgel conformal coatings. BIOMATERIALS 2008 29(35): 4605-4615.

[11] Wagner H, Surface replacement arthroplasty of the hip. Clin. Orthop 1978; 134:102-130.

[12] Head, WC. Wagner surface replacement arthroplasty of the hip: analysis of fourteen failures in fortyone hips. J Bone Joint Surg [Am]1981; 63-A:420-427.

[13] Capello, WN, Trancik, TM, Misamore, G, Eaton, R. Analysis of revision surgery of resurfacing hip Arthroplasty. Clin Orthop 1982; 170:50-55.

[14] Bierbaum, BE, Sweet, R. Complications of resurfacing arthroplasty. Orthop Clin North Am 1982; 13:761-775.

[15] Head, WC. The Wagner surface replacement arthroplasty. Orthop Clin North Am 1982; 13:789-797.

[16] Freeman, MA, Bradley, GW. ICLH surface replacement of the hip: an analysis of the first 10 years. J Bone Joint Surg [Br] 1983; 65-6:405-1.

[17] Daniel, J, Pynset, PB, McMinn, DJW. Survival analysis of metal-on-metal hip resurfacing in patients under the age of 55 years with osteoarthritis. J. Bone Joint Surg. [Br], 2004; 86-B:177-84.

[18] Pandit, H, Glyn-Jones, S, McLardy-Smith, P, Gundle, R, Whitwell, D, Gibbons, CL, Ostlere, S, Athanasou, N, Gill, HS, Murray, DW. Pseudotumours associated with metal-on-metal hip resurfacings. J. Bone Joint Surg. Br. 2008 Jul; 90(7):847-51. 
[19] Dunstan, E, Ladon, D, Whittingham-Jones, P, Carrington, R, Briggs, TWR. Chromosomal Aberrations in the Peripheral Blood of Patients with Metal-on-Metal Hip Bearings, The Journal of Bone and Joint Surgery (American). 2008; 90:517-522.

[20] Rahaman, MN, Bal, BS, Garino, JP, Ries, M, Yao, A. Ceramics for Prosthetic Hip and Knee Joint Replacement, J. Am. Ceram. Soc. 2007; 90 [7]:1965-1988.

[21] Nygren, M, Shen, Z. On the preparation of bio-, nano- and structural ceramics and composites by spark plasma sintering. Solid State Sciences, 2003 January; 5(1):125-131

[22] Yoshimura, M, Noma, T, Kawabata K, Somiya, S. Role of $\mathrm{H}_{2} \mathrm{O}$ on the degradation Process of of YTZP. J. Mater. Sci. Lett. 1987; 6:465-467.

[23] Chevalier, J, Cales, B, Drouin, JM. Low-Temperature Ageing of Y-TZP Ceramics. J.Am. Ceram.Soc. 1999; 82 (8): 2150-2154

[24] Garvie, RC, Hannink, RHJ, Pascoe, RT. Ceramic Steel. Nature. 1975; 258:703.

[25] Sharkness, CM. Hamburger, S, Moore RM, Kaczmarek, RG. Prevalence of Artificial Hips in the United States. J. Long Term Effects Med. Implants, 1992; 2:1-8.

[26] Murase, Y, Kato E, Daimon, K. Stability of $\mathrm{ZrO} 2$ phases in ultrafine $\mathrm{ZrO} 2-\mathrm{Al} 2 \mathrm{O} 3$ mixtures. J. Am. Ceram. Soc. 1986; 69:83-87.

[27] Green, DJ. Critical microstructures for microcracking in A12O3-ZrO2 composites. J. Am. Ceram. Soc. $1982 ; 65: 610-614$

[28] Becher PF.Transient thermal stress behaviour in ZrO2-toughenend Al2O3. J. Am. Ceram. Soc. 1981; 64(1):37.

[29] De Aza, AH, Chevalier, J, Fantozzi, G, Schehl M, Torrecillas, R. Crack growth resistance of alumina, zirconia and zirconia toughened alumina ceramics for joint prostheses. Biomaterials, 2002 February; 23(3):937-945

[30] Pecharromán, C, Bartolomé, JF, Requena, J, Moya, JS, Deville, S, Chevalier, J, Fantozzi, G, Torrecillas, R. Percolative Mechanism of aging in Zirconia-Containing Ceramics for medical applications. Adv. Mater. 2003;15:507-511.

[31] Deville, S, Chevalier, J, Fantozzi, G, Bartolomé, JF, Requena, J, Moya, JS, Torrecillas, R, Díaz, LA. Low temperature ageing of zirconia-toughned alumina ceramics and its implication in biomedical implants. J. Eur. Ceram. Soc., 2003; 23:2975-2982.

[32] Deville, S, Chevalier, J, Dauvergne, C, Fantozzi, G. Bartolomé, JF, Moya, JS and Torrecillas, R. Microstructural Investigation of the Aging Behavior of (3Y-TZP)-A12O3 Composites. J. Am. Ceram. Soc. 2005 May; 88(5):1273-1280.

[33] Nakanishi, T, Sasaki, M, Ikeda, J, Miyaji, F, Kondo, M. Mechanical and phase stability of zirconia toughened alumina. Key Engineering Materials. 2007; 330-332 II:1267-1270.

[34] Pezzotti, G, Yamada, K, Sakakura S, Pitto, RP. Raman Spectroscopic Analysis of Advanced Ceramic Composite for Hip Prosthesis. J. Am. Ceram. Soc. 2008; 91(4):1199-1206.

[35] Choi, S, Awaji, H. Nanocomposites - a new material design concept. Science and Technology of Advanced Materials 2005; 6:2-10. 
[36] De Aza, AH, Chevalier, J, Fantozzi, G, Schehl, M, Torrecillas, R. Slow Crack Growth Behaviour of Zirconia Toughned Alumina Ceramics Processed by Different Methods. J. Am. Ceram. Soc. 2003; 86(1):115-20.

[37] Schehl, M, Díaz LA. Torrecillas, R. Alumina based nanocomposites from powder-alcoxide mixtures. Acta Materialia 2002; 50:1125-1139.

[38] Deville , S, Chevalier, J, Fantozzi, G, Bartolomé, JF, Requena, J, Moya, JS, Torrecillas, R, Díaz, LA. Development of Advanced Zirconia-Toughened Alumina Nanocomposites for Orthopaedic Applications. Key Engineering Materials 2004; 264-268:2013-2016.

[39] Chevalier, J, Deville, S, Fantozzi, G, Bartolomé, JF, Pecharromán, C, Moya, JS, Díaz LA, Torrecillas, R. Nanostructured Ceramic Oxides with a Slow Crack Growth Resistance Close to Covalent Materials, Nano Letters 2005; 5(7):1297-1301.

[40] Chevalier, J, De Aza, AH, Fantozzi, G, Schehl, M, Torrecillas, R. Extending the Lifetime of Ceramic Orthopaedic Implants, Advanced Materials 2000;12(21):1619-1621.

[41] Nawa, M, Nakamoto, S, Sekino, T, Niihara, K. Tough and strong Ce-TZP/Alumina nanocomposites doped with titania. Ceram. Inter. 1998; 24:497-506.

[42] Tanaka, K, Tamura, J, Kawanabe, K, Nawa, M, Uchida, M, Kokubo, T, Nakamura, T. Phase stability after aging and its influence on Pin-on-Disk wear properties of Ce-TZP/A12O3 nanocomposite and conventional Y-TZP. J. Biomed. Mater. Res. 2003; 67A:200-207.

[43] Tanaka, K, Tamura, J, Kawanabe, K, Nawa, M, Oka, M, Uchida, M, Kokubo, T, Nakamura, T. Ce$\mathrm{TZP} / \mathrm{A} 12 \mathrm{O} 3$ nanocomposites as a bearing material in total joint replacement. J. Biomed. Mater. Res. 2002; 63:262-270.

[44] Uchida, M, Kim, HM, Kokubo, T, Nawa, M, Asano, T, Tanaka, K, Nakamira, T. Apatite-forming ability of a Zirconia/Alumina nano-composite induced by chemical treatment. Inc. J. Biomed. Mater. Res. 2002; 60:277-282

[45] Benzaid, R, Chevalier, J, Saâdaoui, M, Fantozzi, G, Nawa, M, Diaz, LA, Torrecillas, R. Fracture toughness, strength and slow crack growth in a ceria stabilized zirconia-alumina nanocomposite for medical applications, Biomaterials, 2008; 29(27):3636-3641.

[46] Torrecillas, R, Díaz, LA. Nanocomposites for biomedical applications. International Journal of Materials Research 2008. In press.

[47] Richter, HG, Willmann, G. Realiability of ceramic components for total hip endoprostheses. British Ceramic Transactions. 1999; 98(1):29-34.

[48] Piconi, C, Maccauro, G, Pilloni, L, Burger, W, Muratori, F, Richter, HG. On the fracture of a zirconia ball head. J. Mater. Sci.: Mat. In Med. 2006; 17:289-300.

[49] Richter, HG. Fractography of bioceramics. Key Eng. Mat. 2002; 223:157-180.

[50] Deville, S, Chevalier J, Gremillard, L. Influence of surface finish and residual stresses on the ageing sensitivity of biomedical grade zirconia. Biomaterials 2006; 27:2186-2192.

[51] Burlington, B, D. editor. Steam Re-sterilization causes deterioration of zirconia ceramic heads of total hip prostheses. US Food and Drug Administration Warning, 1997 May; 21.

[52] Willmann, G. Ceramic Femoral Heads for Total Hip Arthroplasty, Adv. Eng. Mat. 2000; 2(3):114-122. 
[53] Allain J, Roudot-Thoraval F, Delecrin J, Anract P, Migaud H, Goutallier, D. Revision total hip arthroplasty performed after fracture of a ceramic femoral head. A multicenter survivorship study. J. Bone Joint Surg. Am 2003; (85-A):825-830.

[54] Ritchie, RO, Gilbert, CJ, McNaney, JM. Mechanics and mechanisms of fatigue damage and crack growth in advanced materials. Int. J. Solids Struct. 2000; 37(1-2):311-329.

[55] Chevalier, J, Deville, S, Fantozzi, G, Bartolomé, JF, Pecharroman, C, Moya, JS, Torrecillas, R. Advanced Nanocomposite Materials for Orthopaedic Applications. II. Reliability assessment. Journal of Biomedical Materials Research Part B: Applied Biomaterials, 2008, In press.

[56] Moya, JS, Lopez-Esteban, S, Pecharroman, C. The challenge of ceramic/metal microcomposites and nanocomposites. Prog. Mater. Sci. 2007;52(7):1017-1090.

[57] Bartolomé, JF, Gutierrez-Gonzalez, CF, Pecharroman, C, Moya JS. Synergistic toughening mechanism in 3Y-TZP/Nb composites. Acta Materialia. 2007; 55:5924-5933.

[58] Moya, JS, Diaz, M, Gutierrez-Gonzalez, CF, Diaz, LA, Torrecillas, R, Bartolomé, JF. Mulliterefractory metal (Mo, Nb) composites. J. Eur. Ceram. Soc. 2008; 28(2):479-491.

[59] Gutierrez-Gonzalez, CF, Bartolomé, JF. Damage tolerance and R-curve behaviour of $\mathrm{Al}_{2} \mathrm{O}_{3}-\mathrm{ZrO}_{2}-\mathrm{Nb}$ multiphase composites with synergistic toughening mechanism. J. Mater. Res. Vol. 2008; 23(2):570-578.

[60] Bartolome, JF, Diaz, M, Moya, JS. Influence of the metal particle size on the crack growth resistance in mullite-molybdenum composites. J. Am. Ceram. Soc. 2002; 85(11):2778-2784.

[61] Bartolome, JF, Requena, J, Moya, JS, Li, M, Guiu, F. Cyclic fatigue crack growth resistance of Al2O3-A12TiO5 composites. Acta Mater. 1996; 44(4):1361-1370.

[62] Bartolomé, JF, Gutierrez-Gonzalez, CF, Torrecillas, R. Mechanical properties of alumina-zirconia-Nb micro-nano hybrid composites. Composite Sci. Technol. 2008;68(6):1392-1398.

[63] O’Brien, B, Stinson, J, Carroll, W. Development of a new niobium-based alloy for vascular stent applications. Journal of the Mechanical Behavior of Biomedical Materials 2008; 1:303-312.

[64] Tomsia, AP, Saiz, E, Song, J, Bertozzi, CR. Biomimetic bonelike composites and novel bioactive glass coatings. Adv. Eng. Mater. 2005; 7(11):999-1004.

[65] Pazo, A, Saiz, E, Tomsia, AP. Silicate glass coatings on Ti-based implants. Acta Mater 1998; 46:2551-2558.

[66] Gomez-Vega, JM, Saiz, E, Tomsia, AP, Oku, T, Suganuma, K, Marshall, GW, Marshall, SJ. Novel bioactive functionally graded coatings on Ti6Al4V. Adv. Mater. 2000; 12:894-898.

[67] Gomez-Vega, JM, Saiz, E, Tomsia, AP. Glass-based coatings for titanium implant alloy. J Biomed. Mater. Res. 1999; 46:549-559.

[68] Lopez-Esteban, S, Saiz, E, Fujino, S, Oku, T, Suganuma, K, Tomsia, AP. Bioactive glass coatings for orthopedic metallic implants. J. Eur. Ceram. Soc. 2003; 23:2921-2930.

[69] Pavon, J, Jimenez-Pique, E, Anglada, M, Lopez-Esteban S, Saiz, E, Tomsia, AP. Stress-corrosion cracking by indentation techniques of a glass coating on Ti6Al4V for biomedical applications, J. Eur. Ceram. Soc. 2006; 26(7):1159-1169.

[70] Lopez-Esteban, S, Gutierrez-Gonzalez, CF, Gremillard, L, Saiz, E, Tomsia AP. Interfaces in graded coatings on titanium-based implants. J Biomed Mater Res Part A 2009 88A(4):1010-1021]. 
[71] Huiskes R, Weinans H, Vanrietbergen B. The relationship between stress shielding and boneresorption around total hip stems and the effects of flexible materials. Clin Orthop Relat R 1992 274:124134].

[72] Koester, KJ, Ager III, JW, Ritchie, RO. The true toughness of human cortical bone measured with realistically short cracks. Nature Materials. 2008, (7):672-677.

[73] Currey, JD. Bones: Structure and Mechanics. Princeton Univ. Press, Princeton, NJ; 2002.

[74] Saiz, E, Gremillard, L, Menendez, G, Miranda, P, Gryn, K, Tomsia, AP. Preparation of porous hydroxyapatite scaffolds. Materials Science and Engineering 2007; C 27:546-550.

[75] Hollister, SJ. Porous scaffold design for tissue engineering. Nature Materials 2005; (4):518.

[76] Wong, WH, Mooney, D. in: Atala, A, Mooney, DJ. (Eds.), Synthetic Biodegradable Polymer Scaffolds.1997, p. 51. Birkhauser, Boston.

[77] Shors, EC, Holmes, RE. in: Hench, LL, Wilson, J. (Eds.). An Introduction to Bioceramics, World Scientific, New Jersey, 1993, p. 181.

[78] Lewis, JA, Smay, JE, Stuecker, J, Cesarano III, J. Direct Ink Writing of Three-Dimensional Ceramic Structures. J. Am. Ceram. Soc. 2006; 89(12):3599-3609.

[79] Deville, S, Saiz, E, Tomsia, AP. Freeze casting of hydroxyapatite scaffolds for bone tissue engineering. Biomaterials. 2006; 27:5480-5489.

[80] Deville, S, Saiz, E, Nalla, RK, Tomsia, AP. Freezing as a Path to Build Complex Composites. Science. 2006; 311:515-518.

[81] Hindsén, M, Carlsson, AS, Möller, H. Orthopaedic metallic implants in extremity fractures and contact allergy. Journal of the European Academy of Dermatology \& Venereology. 1993; 2(1):22-26.

[82] Hallab, N, Jacobs, JJ, Black, J. Hypersensitivity to metallic biomaterials: a review of leukocyte migration inhibition assays, Biomaterials. 2000 July; 21(13):1301-1314.

[83] Hallab, N, Merritt, K, Jacobs, JJ. Metal Sensitivity in Patients with Orthopaedic Implants. The Journal of Bone and Joint Surgery. 2001; 83:428. 